Pre-publication version: accepted for publication by Urban History 23/9/19, deposited by the authors with UCL RPS 24/9/19

\title{
Mapping spatial cultures: contributions of space syntax to research in the urban history of the nineteenth-century city
}

\author{
Sam Griffiths ${ }^{1}$ Laura Vaughan ${ }^{1}$ \\ ${ }^{1}$ Space Syntax Laboratory, Bartlett School of Architecture, UCL, UK
}

Keywords: space syntax, mapping, map analysis, spatial cultures, interdisciplinarity

\begin{abstract}
The theory and methods of space syntax can help rebalance the prevailing cultural perspective, which views maps as ideological representations, with an analytical approach that emphasises maps as sources for understanding space and spatial relationships embedded in built forms. The quantitative descriptions of urban street networks produced by space syntax analyses can be used to formulate and test hypotheses about patterns of urban movement, encounter and socio-economic activity in the past, that can help in the interpretation of other historical source materials to give an overall account of urban spatial culture. In this article the authors explain how space syntax, an theory and method originally developed in the field of architectural research, is making a distinctive contribution to research in social and urban history. The key principles of the method are explained by clarifying the relationship of space syntax to HGIS (Historical Geographical Information Systems) and through a worked example of a research undertaken into political meeting places. A survey of research into the urban history of the nineteenth-century city using space syntax is used to highlight a number of important methodological themes and also demonstrates the range of innovative contributions this interdisciplinary approach is able to advance. A final, theoretical, section reflects on maps and the practice of 'mapping' from a space syntax perspective.
\end{abstract}


Pre-publication version: accepted for publication by Urban History 23/9/19, deposited by the authors with UCL RPS 24/9/19

\section{Introduction: space syntax GIS and perspectives on urban mapping}

The dominant focus of mapping research in urban history focuses around the implementation of GIS (Geographical Information Systems) technologies for historical research, a field known as Historical GIS (HGIS). ${ }^{1}$ By assigning two-dimensional coordinates from a given cartographic projection to diverse archive source materials in a process known as georeferencing, GIS enables 'messy' historical data to be precisely located on maps and plans of urban space. Mapped data can help identify relationships between phenomena that may not be self-evidently connected by revealing their shared locative dimension. While GIS offers a powerful platform for the mapping, analysis and visualization of historical spatial datasets, however, the relationship of these geographically spatialized data to the structure of urban space, most notably with respect to urban street networks, is rarely addressed systematically. One reason for this is that much historical data (and data in general) lends itself to aggregation at the scale of the administrative boundary at which it was originally collected; another is simply that, in the absence of a specific spatial-morphological proposition, it is not clear how an understanding of street network structure can advance historians' interpretation of urban life itself.

Space syntax takes the town plan or map as the starting point for empirical research into the historical relationship between urban space and urban life on the basis of the network (i.e. relational) analysis of urban space viewed configurationally as a differentiated system of spaces. In this it differs from culturally determined approaches to urban history in which historical maps and cartographies of data are typically treated as illustrative (i.e. to be explained contextually), rather than as artefacts that carry analytical weight (i.e. contribute explanations) in their own right. One reason for this is because the relationship of many contemporary urban historians to maps remains ambivalent. Many, if not most, consider maps much as they would texts, as unreliable and compromised productions of particular social and cultural milieus. Such critical scrutiny of maps is essential but becomes problematic when it sustains, sometimes rather too axiomatically, the assumption that the primary value of maps to historical research is to reveal the ideologies that produced the representation or even the urban environment itself, rather than to probe its surface for clues as to how people actually

\footnotetext{
${ }^{1}$ I. Gregory and P.S. Ell, Historical GIS: Technologies, Methodologies, and Scholarship (Cambridge, 2007).
} 
Pre-publication version: accepted for publication by Urban History 23/9/19, deposited by the authors with UCL RPS 24/9/19

lived in the past.

The dominance of the cultural emphasis on textuality in historical studies since the 1990s has, we argue, resulted in an epistemological blind spot that has obstructed urban historians from thinking about the ways in which maps can be approached empirically as sources for understanding the urban built environment as an inhabited space. ${ }^{2}$ A shared enthusiasm for maps across the interdisciplinary spatial humanities still sits uneasily with many social and cultural historians' sense that social-scientific 'mapping' techniques, largely associated with GIS, tend to privilege technical expertise and the demands of the methodological model over a contextual understanding of the source material. Yet from a space syntax perspective cartographic representations are morphologically as much as culturally encoded, offering detailed descriptions of the material affordances of historical built environments as much as codifications of the symbolic ordering of urban landscapes.

The central proposition of space syntax theory for urban-scale analysis is that the spatial configuration of the street network provides researchers with the elusive link between what the historical geographer Pooley refers to as 'patterns on the ground' (the material city of built forms) and the corresponding social patterns they mediate and reproduce. ${ }^{3}$ Space syntax analysis of maps and plans produces both visual and numerical descriptive data which can inform propositions, for example about patterns of movement, encounter and land use in the past, that can both be qualified by non-cartographic historical sources and help in their interpretation. This is especially powerful when historical sources exist at the resolution of the street or building plot (for example census or business directory data). Such sources can be mapped onto contemporaneous plans of the street network - the 'shape of habitable space' as Penn calls it, rather than to relatively abstract area-based political or administrative boundaries, as is the norm in much HGIS scholarship. ${ }^{4}$ Analysis of street networks using space syntax allows the relative accessibility of different street spaces to be quantified, thereby enabling the delineation of urban activities such as the diversity of business types or

\footnotetext{
${ }^{2}$ S. Griffiths, 'GIS and research into historical "spaces of practice": overcoming the epistemological barriers', in C. Travis and A. von Lünen (eds), History and GIS: Epistemologies, Considerations and Reflections (Dordrecht, 2013), 153-172.

${ }^{3}$ C. Pooley, 'Patterns on the ground: urban form, residential structure and the social construction of space', in M.J. Daunton (ed.), The Cambridge Urban History of Britain 1840-1950, iii, (Cambridge, 2000), 429-65; for a space syntax perspective see B. Hillier and L. Vaughan, 'The city as one thing', Progress in Planning, 67, 3 (2007), 205-230.

${ }^{4}$ A. Penn, 'The shape of habitable space', Proceedings of the $4^{\text {th }}$ International Space Syntax Symposium (London, 2007), 62:1-16, http://spacesyntax.net/symposia-archive/SSS4/fullpapers/62Penn-habitablespace.pdf accessed 14 Apr 2019.
} 
Pre-publication version: accepted for publication by Urban History 23/9/19, deposited by the authors with UCL RPS 24/9/19

the structure of a kinship network, to be read back from the plan as socio-spatial as much as a socio-economic phenomena.

The space syntax analysis of urban street network is typically implemented in a GIS environment but space syntax was not developed as a specifically GIS application, having been developed for the purposes of architectural research and possessing its own portfolio of dedicated (mainly open-source) software. ${ }^{5}$ Implementation of space syntax in a GIS environment is now standard but the emphasis on the analysis of built form configuration requires a rethink of HGIS epistemology. ${ }^{6}$ Visualizations of the urban built environment made using GIS often have a contextual rather than explanatory purpose, with the georeferenced basemap providing the background to the foregrounded arrangement of georeferenced data that constitutes the primary analytical focus. Here the agency of the street network itself in explaining the patterning of historical data, is likely to be subsumed in a generalized topographical description (for example, also noting the location of rivers, central areas low lying regions) that comprises a necessary context but with little interpretative power. Such a contextual approach does not sufficiently challenge the widely held view amongst urban historians that equates a research focus on the spatial arrangement of urban built form less with the emergent patterning of everyday routines than with forces of ideological domination and control. ${ }^{7}$ The effect of this strongly cultural emphasis, it is argued, is effectively to dematerialize the 'noise' of everyday urban life and repress the explanatory potential of built form in explain its dynamics.

In this spirit we deploy the term 'spatial culture" ${ }^{8}$ as a motif to propose how space syntax, both as a conceptual scheme and formal method of map and plan analysis, positions its

\footnotetext{
${ }^{5}$ The most widely used space syntax software is DepthmapX. DepthmapX is available on an open source license from UCL's Space Syntax Laboratory http://varoudis.github.io/depthmapX/ accessed 24 Jan 2019. For the integration of space syntax software with QGIS software see: J. Gil, T. Varoudis, K. Karimi and A. Penn, 'The space syntax toolkit: integrating DepthmapX and exploratory spatial analysis workflows in QGIS', In K. Karimi, L. Vaughan, K. Sailer, G. Palaiologou and T. Bolton (eds), Proceedings of the 10th International Space Syntax Symposium, (London, 2015), 148:1-16, http://discovery.ucl.ac.uk/1490063/ accessed 14 April 2019

${ }^{6}$ Griffiths, "GIS and research into historical "spaces of practice"'; see also C.E. Jones, S. Griffiths, M. Haklay and L. Vaughan, 'A multi-disciplinary perspective on the built environment: space syntax and cartography - the communication challenge', in: D. Koch, L. Marcus and J, Steen (eds), Proceedings of the 7th International Space Syntax Symposium, (Stockholm, 2007), 48:1-12, http://discovery.ucl.ac.uk/15294/ accessed 14 Apr 2019.

${ }^{7}$ The influence of Michael Foucault's panoptican is pervasive here: M. Foucault, Discipline and Punish: the Birth of the Prison, (London, 1977).

${ }^{8}$ B. Hillier, 'The architecture of the urban object', Ekistics, 56 (1989), 334-335; S. Griffiths and A. von Lünen, 'Preface', in Griffiths and von Lünen (eds), Spatial Cultures: New Perspectives on the Social Morphology of Cities Past and Present (Abingdon, 2016), $\mathrm{xx}-\mathrm{xxx}$.
} 
Pre-publication version: accepted for publication by Urban History 23/9/19, deposited by the authors with UCL RPS 24/9/19

contribution to the research agenda of urban history. Research in urban spatial cultures is specifically concerned with the proposition that the material or 'artefactual' arrangements of built forms is generative of social life through its historical role in mediating the production, reproduction and material embedding of social information across space and time. ${ }^{9}$ This information is continually re-embodied in spatial practices (such as movement and encounter patterns) that are discretely located in space and time. ${ }^{10}$ It proposes that the spatialmorphological analysis of town plans used in conjunction with available evidence indicating how people lived, worked and socialized in urban space, can provide insights into the lowlevel hum that sustained the quotidian life of towns and cities. Following this introduction the remainder of this article is divided into three main sections: the first discusses research space syntax research in the social history of the nineteenth-century city in order to highlight a number of important methodological themes; the second critically examines the theoretical principles of space syntax mapping methods, and the third identifies some historiographical contexts of space syntax research.

\section{Space syntax research in the social history of the nineteenth-century city}

Space syntax has been applied to many periods of urban history, not only by space syntax researchers but also by specialists from other fields, most notably archaeologists and historians of cities in the classical world. ${ }^{11}$ Space syntax research in nineteenth-century cities has, we propose, now reached a level maturity which is enabling it to extend beyond its own dedicated field to become part of a broader interdisciplinary conversation with urban and social historians. ${ }^{12}$ In developing this dialogue space syntax researchers have been attracted to a previous generation of historians and historical-geographers of the nineteenth-century city who used social cartography to visualize census data in exploring questions such as the

\footnotetext{
${ }^{9}$ S. Griffiths, 'Temporality in Hillier and Hanson's theory of spatial description: some implications of historical research for space syntax', Journal of Space Syntax, 2, 1 (2011), 73-96, http://joss.bartlett.ucl.ac.uk/journal/index.php/joss/article/view/58 accessed 14 Apr 2019; also F. Weissenborn, 'After structure: expression in built form', Journal of Space Syntax, 6, 1 (2015), 34 — 48, http://joss.bartlett.ucl.ac.uk/journal/index.php/joss/article/viewFile/204/pdf accessed14 Apr 2019.

${ }^{10}$ B. Hillier and J. Hanson, The Social Logic of Space (Cambridge, 1984), 45.

${ }^{11} \mathrm{~S}$. Griffiths, 'The use of space syntax in historical research: current practice and future possibilities', in M. Greene, J. Reyes and A. Castro (eds), Proceedings of the Eighth International Space Syntax Symposium (Santiago, Chile, 2012), 8193:1-26, http://sss8.cl/8193.pdf accessed 14 Apr 2019; H. Stöger, 'The ancient city and Huizinga's Homo Ludens', in Griffiths and von Lünen, Spatial Cultures, 15-31. For an early modern focus, S. Psarra, The Venice Variations: Tracing the Architectural Imagination, (UCL Press, 2018), chapters 1-2, https://www.uclpress.co.uk/products/107619 accessed 14 Apr 2019.

${ }^{12}$ Researchers from UCL's Space Syntax Laboratory hosted panel sessions at the Urban History Group Annual Conference, Robinson College, University of Cambridge (March/ April 2016) and Royal Holloway, University of London (March 2017), and presented research papers at The European Association of Urban Historians Conference, Helsinki (August, 2016) and Rome (2018), to select just a few instances of this interdisciplinary nexus.
} 
Pre-publication version: accepted for publication by Urban History 23/9/19, deposited by the authors with UCL RPS 24/9/19

residential distribution of migrant groups and residential segregation, and more generally to those scholars concerned with the built environment of the city as much as with its representation. ${ }^{13}$ Space syntax research in historical mapping positions itself in relation to this tradition in urban history, which, we believe, still has a contribution to make. This section reports on the growing corpus of studies using space syntax to examine how the configuration of urban form helped to shape the social history of nineteenth-century English cities and highlights five important methodological themes that are common, to a greater or lesser extent, across this body of work.

\section{Identifying the spatial-morphological question in the historical question ${ }^{14}$}

A recent interdisciplinary collaboration (2016-2017), between Sam Griffiths at UCL's Space Syntax Laboratory and the historian of popular protest Katrina Navickas (University of Hertfordshire ${ }^{15}$ explores how space syntax analysis can be deployed in conjunction with historical data to yield fresh insights into the relationship of urban space and diverse sites of political meeting. ${ }^{16}$ The project uses an ArcGIS platform to join political meetings data compiled and georeferenced manually by Dr Navickas, to spatial-morphological data produced using space syntax (i.e. configurational) analysis of the historical street networks of Manchester and Sheffield. ${ }^{17}$ Analysing the structure of an historical street network makes it possible to access the spatial, as well as the social, relationships of nineteenth-century political meetings. ${ }^{18}$

\footnotetext{
${ }^{13}$ H. J. Dyos, Victorian Suburb: a Study of the Growth of Camberwell (Leicester, 1961); C. Pooley, 'The residential segregation of migrant communities in mid-Victorian Liverpool', Transactions, Institute of British Geographers 2, new series (1977), 364-382; D. Cannadine, 'Residential differentiation in nineteenth-century towns: from shapes on the ground to shapes in society', in J.H. Johnson and C. Pooley (eds), The Structure of Nineteenth Century Cities (London; New York1982), 235-281. A recent space syntax contribution to this tradition of work is J. R. O'Brien and S. Griffiths 'Relating urban morphologies to movement potentials over time: a diachronic study with space syntax of Liverpool, UK', in T. Heitor, M. Serra, P. Silva, M. Bacharel and L. Cannas da Silva, (eds), Proceedings of the 11th Space Syntax Symposium, (Lisbon, 2017), 98.1-11 http://discovery.ucl.ac.uk/1566798/ accessed 14 Apr 2019.

${ }^{14}$ The authors would like to acknowledge Dr Katrina Navickas, Reader in History at the University of Hertfordshire, for her integral role in developing the political meetings research presented in this section and for permission to represent her data in this context.

${ }^{15}$ The research project: 'Applying space syntax methods to historical data: mapping popular political meetings in 19th century British cities' is part funded by an Architectural Research Fund grant (2016) from UCL's Bartlett School of Architecture and is expected to conclude in 2019.

${ }^{16}$ K. Navickas, The Politics of Space and Place, 1789-1848 (Manchester, 2015).

${ }^{17}$ A part of the newspaper data was text-mined using a Python code developed with the British Library Labs team in their Digital Scholarship department - see: K. Navickas and A. Crymble, 'From Chartist newspaper to digital map of grassroots meetings, 1841-1844: documenting workflows', Journal of Victorian Culture, 22, 2 (2017).

${ }^{18}$ S. Griffiths, K. Navickas and D. Blerta, 'Political meeting places in Manchester and Sheffield c.1780-1860: the built environment as a quotidian source of political agency'. Unpublished paper presented to the European Association of Urban Historians, Rome 31 Aug 2018.
} 
Pre-publication version: accepted for publication by Urban History 23/9/19, deposited by the authors with UCL RPS 24/9/19

While the project certainly aims at methodological innovation, its primary purpose is rooted in an historical question. Studies of industrial cities Britain have traditionally focussed on socio-economic and environmental conditions rather than on the arrangement of built form in explaining occurrences of political meetings. Literary sources and contemporary descriptions inflected with romanticism often represent the experience of the industrial city as intrinsically traumatic and oppressive. This portrayal informs an enduring tradition in urban sociology and town planning that represents the industrial city as a symptom (one might say a symbol) of an unjust society. As a commonly held, almost a priori assumption, this view rather silences alternative readings of the industrial city as a highly complex social space characterized by distinctive and dynamic patterns of co-presence, movement and encounter between people, information, symbols and objects. ${ }^{19}$ It follows that the focus of historical research has been on the large outdoor meeting rather than more routine popular political meeting that were the most characteristic form of political action in the industrial city.

The research project was implemented in a two-phase time-series a database of over 1000 political meetings and meeting places in Manchester (715 entries) and Sheffield (249 entries) between 1775 and 1850. A total of 185 sites in Manchester and 70 sites in Sheffield were identified and categorised. The majority of sites in both cities were pubs and inns, but they also included squares, assembly rooms, court houses, streets and theatres and purpose-built meeting buildings, among others. Two historical base maps for each city were selected from beginning and end of the time-series: Green's 1794 map of Manchester; and William Fairbanks'1797 map of Sheffield; and the two 5-inch to the mile first edition (1849-50) Ordnance Survey maps of both cities. These base-maps were first traced in ArcGIS to produce simplified road-line maps of the street networks which were then converted to space syntax axial and segment maps in DepthmapX space syntax software. This process produces a range of configurational variables associated with each road segment for analysis. A further stage of cartographic analysis of both cities, using methods from Conzenian urban morphology and space syntax research, provided a range of formal descriptions of urban spatial structure from

\footnotetext{
${ }^{19}$ For example, L. Mumford, The City in History, (Harmondsworth, 1961). Mumford believed the industrial city was essentially dehumanizing. Whatever the justice of this view in itself, from a $21^{\text {st }}$ century standpoint it is clearer how its influence on post-war architectural modernism also expressed a class-based distaste for industrial cities that too easily associated environmental degradation with social degradation- a form of environmental determinism. See R. Evans, 'Rookeries and model dwellings', in Translations from Drawing to Buildings and Other Essays (London, 1997), 94-117.
} 
Pre-publication version: accepted for publication by Urban History 23/9/19, deposited by the authors with UCL RPS 24/9/19

the micro-morphological domain of the street-building interface to the street network of entire

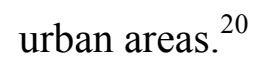

The next stage of analysis required joining the spatial configurational data (for each road segment) to the georeferenced point data (describing each political meeting) in the GIS. This spatial join enabled analysis of the relationship between the spatial structure of the urban built environment and the location of political meetings to be approached through the street network rather than being aggregated to arbitrary administrative or political boundaries imposed onto this space. ${ }^{21}$

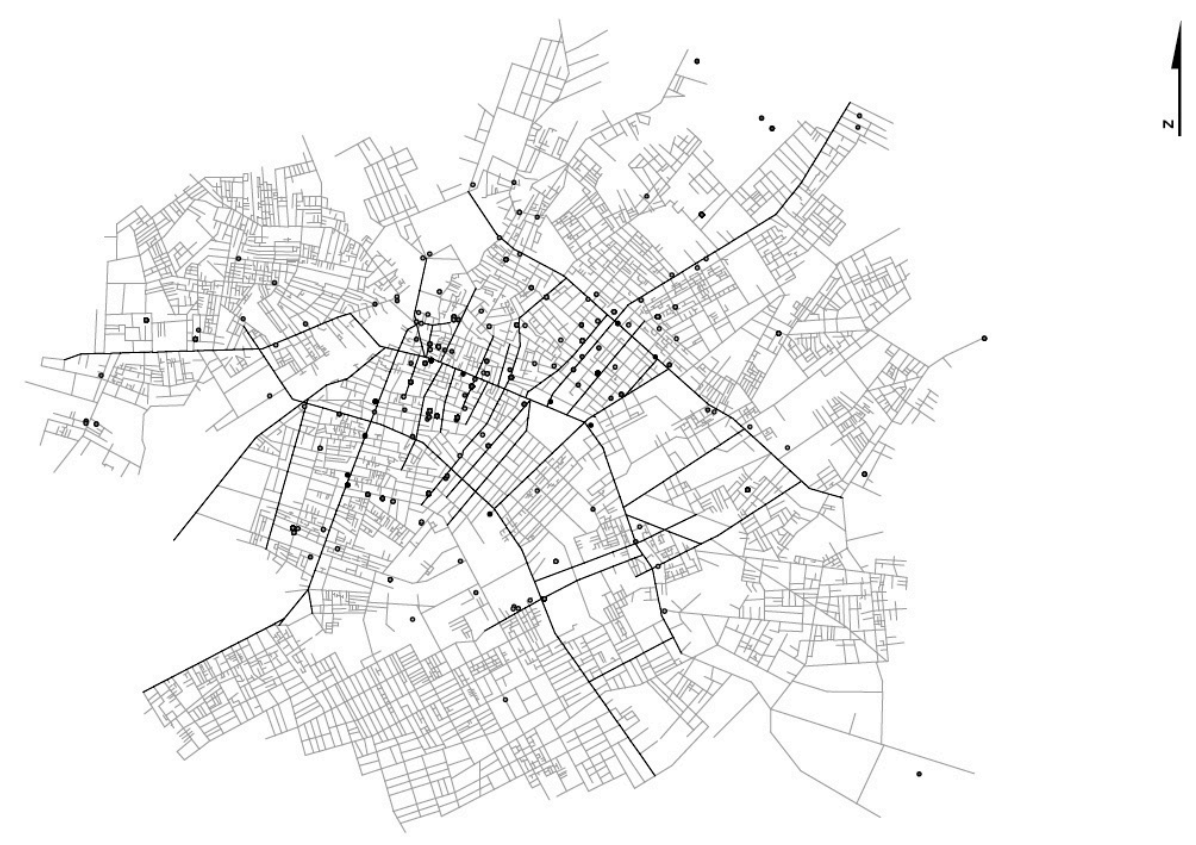

Figure 1: Locations of political meeting places overlaid on space syntax street network analysis of Manchester in 1849, highlighting in dark grey the top $20 \%$ most accessible segments Image by Blerta Dino, Sam Griffiths and Katrina Navickas

Figure 1 visualizes the location of all the political meeting places in the Manchester database overlaid on a space syntax road segment map showing the 20 per cent most accessible segments that highlights the probable urban scale structure of movement. Once the spatial-

\footnotetext{
${ }^{20}$ See also: S. Griffiths, C.E. Jones, L. Vaughan and M. Haklay, 'The persistence of suburban centres in Greater London: combining Conzenian and space syntax approaches', Urban Morphology 14, 2 (2010) 85-99.

${ }^{21}$ See also below page 15
} 
Pre-publication version: accepted for publication by Urban History 23/9/19, deposited by the authors with UCL RPS 24/9/19

morphological data was joined to the historical meetings data in the GIS the different categories of political meeting and meeting site were spatially profiled by assigning mean configurational values which could be compared. Three spatial variables from space syntax model are key to the profiling exercise and subsequent interpretation:

1. Accessibility: refers to how relatively close one urban space (e.g.) street or square is to another; that is how integrated or segregated the space is in relation to all other spaces in the urban system (or a subset of those spaces); the theory proposes that integrated space is more likely to be a movement destination than segregated space

2. Foreground and background networks: in space syntax a 'foreground network' typically refers to the structure of space that connects different centres and subcentres of a city and is associated with higher levels of movement, encounter, commerce and social co-presence, and more generally, with socially 'generative' action; a 'background' network typically refers to residential areas that are embedded in interstices of the foreground network and are said to be socially 'conservative' in the sense of reproducing existing social relationships, or at least localizing dissent;

3. Accessibility is pervasive and relative to urban scale: a spatial element such as a high street may function as an interface between a dense 'noise' of localized movements and proportionately fewer movements at relatively larger scales;

The baseline profiling exercise showed how, in Manchester and Sheffield, political meetings took place in higher than average accessibility locations both at the urban scale and at the neighbourhood scale - often taking place at the interface of both. This tendency was stronger in Manchester than in Sheffield - suggesting that political meeting places in Manchester showed greater tendency to diversify their locations as the city's built environment expanded in the first half of the nineteenth-century. ${ }^{22}$

The picture emerging from the project is that in the cities of Sheffield, and especially Manchester, distinctive spatial infrastructures for political meeting can be identified. This proposition is useful in rebalancing the weight of research that focusses on the largest and most symbolically significant meetings and meeting places. It grounds new research that takes seriously the particular role of the industrial built environment in offering sufficient spatial-

\footnotetext{
${ }^{22}$ It is intended that the detailed methodology and findings from the political meetings research project should be published in full over the next couple of years.
} 
Pre-publication version: accepted for publication by Urban History 23/9/19, deposited by the authors with UCL RPS 24/9/19

locational niches to sustain a broad range of meeting activities from the local to the city scale of urban space. It shifts the research emphasis from individual meetings to exploring the functional dynamics of a spatial culture of political meeting that was pervasive in industrial cities.

\section{Joining historical data to spatial data precisely and at the highest possible resolution}

An early example of space syntax historical research is a series of studies that drew on the extensive poverty surveys of London produced by Charles Booth in the 1880s and 1890s. Alongside a vast corpus of writing and statistics, the results of Booth's study had been captured on a detailed colour map, first published in 1889 and subsequently revised in 18989, which finely delineated in an array of seven socio-economic gradations from poverty to prosperity. The space syntax analysis used these maps to explore the relationship between physical segregation and poverty in cities by linking the poverty data with the spatial (configurational) attributes of the city's streets and comparing the two. ${ }^{23}$ This work demonstrated how a purely descriptive use of Booth's maps omits an important aspect of his findings regarding the deleterious effects that the specific arrangement of streets in cities, especially the physical segregation of areas, can have on the people living in them. Using a street-based GIS-supported analysis of the distribution of poverty classes, the study found a strong statistical association between poverty and low integration. Further analysis of changes in the street network alongside Booth's second survey ten years later, indicated that there was a circular influence between social and spatial change: slum clearances had had the effect of improving the economic situation of inhabitants of the immediate area, but this masked the fact that the poorest people were forced to move to cheaper (and less spatially privileged) locations elsewhere, breaking vital social ties.

The precise joining of spatialized social data to configurational space syntax data in a GIS is key to using space syntax for historical research. Linkages at the scale of individual addresses, building plots or street are preferable to data that are aggregated to areal boundaries (i.e. polygons) that do not reflect the structure of everyday lived space. Even when data is visualized at the street scale it difficult to intepret what spatial distributions mean without

\footnotetext{
${ }^{23}$ L. Vaughan, D.C. Clark, O. Sahbaz and M. Haklay, 'Space and exclusion: does urban morphology play a part in social deprivation?', Area 37, 4 (2005), 402-412; L. Vaughan, 'The spatial form of poverty in Charles Booth's London', Progress in Planning 67 (2007), 231-250; L. Vaughan, 'Mapping the East End labyrinth', in A. Werner (ed.), Jack the Ripper and the East End (London, 2008), 218-237; L. Vaughan, I. Geddes, 'Urban form and deprivation: a contemporary proxy for Charles Booth's analysis of poverty', Radical Statistics, 99 (2009), 46-73.
} 
Pre-publication version: accepted for publication by Urban History 23/9/19, deposited by the authors with UCL RPS 24/9/19

being an ability to differentiate precisely between areas of the street network on which they are located. Peter Hall's early work in planning history used business directory entries overlaid on schematic maps of London neighbourhoods to analyse the changing spatial distribution of London's furniture industry from the nineteenth century onwards. ${ }^{24}$ In 2016 a research collaboration between the Space Syntax Laboratory and Professor Howard Davis (University of Oregon) revisited this study specifically to examine the role of urban structure in supporting the organization of small-firm urban manufacturing. The space syntax research identified significant differences in the spatial morphologies of the two furniture-making areas (Fitzrovia and Shoreditch) that point to the existence of distinctive spatial cultures of manufacture that can help explain the different development trajectories of these industries, originally identified by Hall. $^{25}$

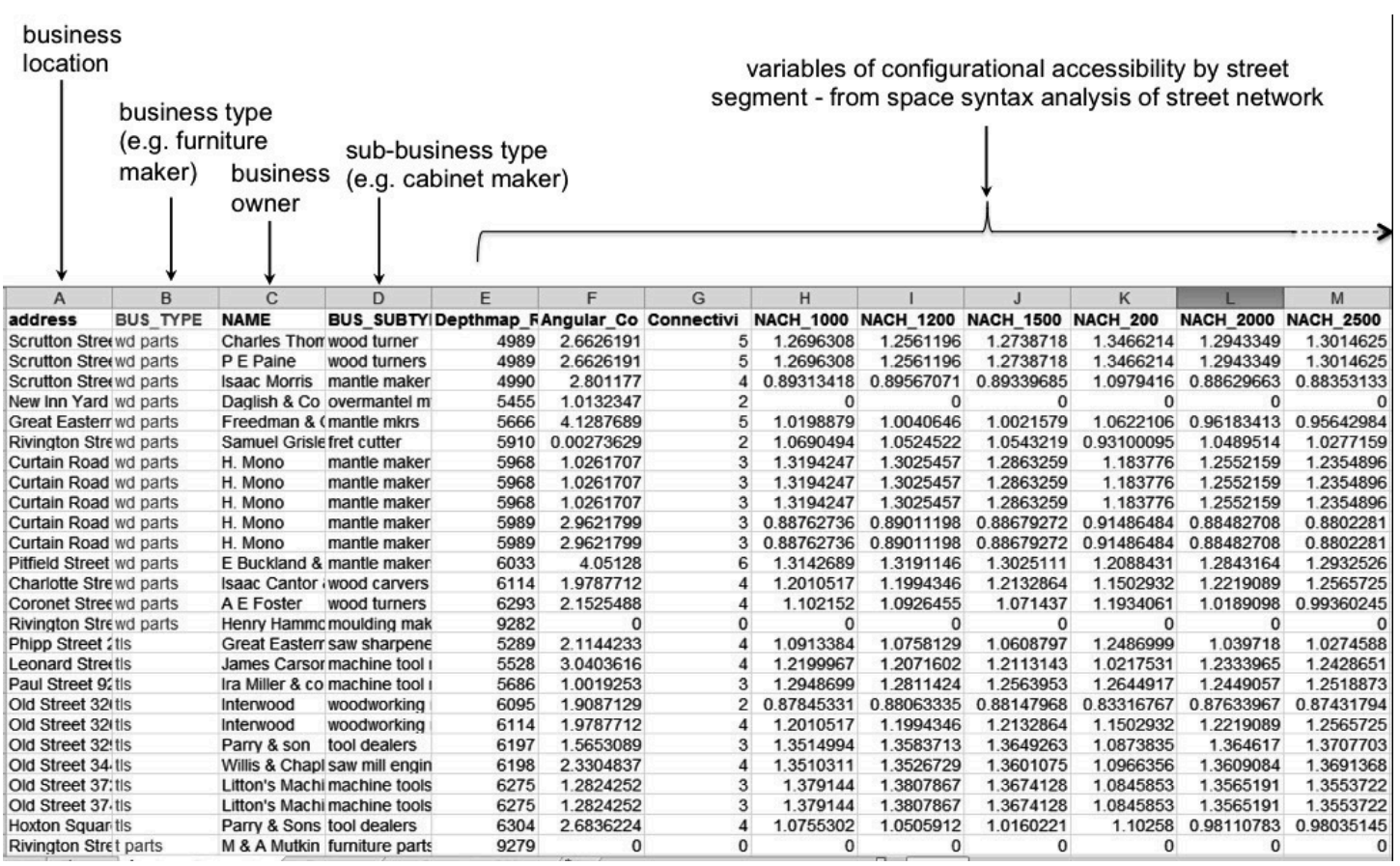

Figure 2: Table of historical and space syntax data joined in GIS to analyse the accessibility of functional specialisms in London's nineteenth-century furniture industry ${ }^{26}$

Image by Blerta Dino and Sam Griffiths

\footnotetext{
${ }^{24}$ P. G. Hall, The Industries of London since 1861 (London, 1962).

${ }^{25}$ L. Narvaez Zertuche, H. Davis, S. Griffiths, B. Dino and L. Vaughan, 'The spatial ordering of knowledge economies: the growth of furniture industry in nineteenth-century London', in T. Heitor, et al (eds), Proceedings 11th International Space Syntax Symposium, 95: 1-22, http://discovery.ucl.ac.uk/10036009/ accessed 14 Apr 2019.

${ }^{26}$ Data on London's furniture industry by permission of Professor Howard Davis University of Oregon.
} 
Pre-publication version: accepted for publication by Urban History 23/9/19, deposited by the authors with UCL RPS 24/9/19

Figure 2 shows a data attribute table produced by the researchers into the spatial dynamics of London's nineteenth-century furniture industry that has been exported from GIS into MS Excel; each row shows one business address. For the project business addresses from trade directories were first linked to individual building plots identified in historical Ordnance Survey maps and Goad fire insurance plans, and secondly, joined with space syntax variables from configurational analysis of London's street network assigned to the equivalent building plots derived.

\section{Qualifying and contextualizing the configurational analysis with archive source material}

Historical research using space syntax relies upon a broad range of source materials to provide contexts, qualifications and ambiguities that are invisible in purely quantitative data. It deploys these additional sources to evaluate and tease out further meanings from sometimes opaque statistical patterns. In one example, space syntax research into the Jewish 'ghetto' (as conventions in social history tend to label it) of London's East End found a much greater level of residential mixing between Jews and non-Jews in the most spatially integrated streets. ${ }^{27}$ This is consistent with the evidence from Charles Booth's notebooks (recording interviews carried out with beat policeman), which points to the existence of a wide range of street types associated with various patterns of ethnic mixing. Kushner draws on oral testimony to similarly argue that boundaries between Jewish and non-Jewish were highly porous with East Enders engaging in many mixed activities. ${ }^{28}$ Yet other oral sources speak of a much harder boundary between so-called Jewish districts and neighbouring streets, for which the Jewish incomer would be seen as an interloper. ${ }^{29}$ The complexities and contradictions in the historical evidence provides the space syntax analysis with an essential interpretative context while suggesting new avenues of enquiry, in this case exploring configurational patterns of ethnic mixing using historical data on kinship patterns, subletting and employment.

\footnotetext{
${ }^{27}$ L. Vaughan and A. Penn, 'The Jewish "Ghetto" - formation and spatial structure', Proceedings of the Third International Space Syntax Symposium (Atlanta, 2001), 55.1-16, http://discovery.ucl.ac.uk/663/ accessed 14 Apr 2019. The source map can be found in C. Russell and H.S. Lewis, The Jew in London, with a map specially made for this volume by Geo. E. Arkell (London, 1901).

${ }^{28}$ T. Kushner, Jew and Non-Jew in the East End of London, in G. Alderman and C. Holmes (eds), Outsiders \& Outcasts: Essays in Honour of William J Fishman (London, 1993), 32-52.

${ }^{29}$ J. White, Rothschild Buildings: Life in an East End Tenement Block 1887-1920 (London, 2003).
} 
Pre-publication version: accepted for publication by Urban History 23/9/19, deposited by the authors with UCL RPS 24/9/19

A related investigation into historical patterns of immigrant economic activity in Manchester and Leeds found that the location of the 'ghetto' was within spatial reach (configurationally speaking) of the economic heart of both cities. ${ }^{30}$ This spatial proximity allowed for multiple social identities to be asserted. While strong kinship ties were maintained within the relatively (spatially) segregated immigrant quarter, these existed in parallel to economic connections to the wider city. In some cases people continued to live in the original place of settlement, while building up a business base in the city centre. Interestingly, Gilliland and Olson have found equivalent findings in a similar study of Jewish settlement patterns in Montreal. ${ }^{31}$ These examples illustrate how space syntax analysis enables the historian to pursue hypotheses regarding the effects of the material organization of the urban setting on urban life through its ability to describe social data in terms of the structure of lived space, and - more specifically - to control for spatial effects when analysing social patterns using a range of archive source materials.

Even without employing detailed space syntax modelling a 'configurational reading' of an historical map can take a step beyond simply considering urban cartography as a simply illustrative of a moment in time. For example, recent work on the Hull-House maps of wage rates and country of origin for a large tract of the city of Chicago in the late $19^{\text {th }}$ century finds that by comparing wage classes present in the main streets and the (highly dilapidated) back alleys, the historian can obtain a clear picture of the spatial juxtaposition of poverty and prosperity. ${ }^{32}$ Adding to the analysis the spatial location of immigrant clusters - and accounting for their particular migration histories through traditional textual sources provides the researcher with an enriched picture of the nature of immigrant settlement patterns at a crucial historical juncture. Reading urban form configurationally means decoding mapped social data to reveal the relational aspects of poverty and segregation at the scale of the street and neighbourhood, providing additional insight into the everyday life of the city. ${ }^{33}$

\footnotetext{
${ }^{30}$ L. Vaughan and A. Penn, 'Jewish Immigrant Settlement Patterns in Manchester and Leeds 1881', Urban Studies, 43 (2006), 653-671.

${ }^{31}$ J. Gilliland and S. Olson, 'Residential segregation in the industrializing city: a closer look', Urban Geography 3, 1 (2010), 29-58. The authors' research highlights how a consideration of the fine scale street hierarchy when mapping rent costs produces an historical understanding of the economic diversity of the city's streets at the time, which contained 'measurably greater internal diversity of land use, dwelling sizes, household rents, and occupation [while] the lesser side streets, lanes, and alleys nurtured microcosms of difference.' 52 .

${ }^{32}$ L. Vaughan, Mapping Society: The Spatial Dimensions of Social Cartography (London, 2018), https://www.uclpress.co.uk/collections/ro popular/products/108697 accessed 14 Apr 2019.

${ }^{33}$ Recent work by M. Poutanen and J. Gilliland serves as parallel example, whereby the textual source - in this instance, the appointments diary of a community Rabbi in Montreal, provide the authors with a source for mapping the social geography
} 
Pre-publication version: accepted for publication by Urban History 23/9/19, deposited by the authors with UCL RPS 24/9/19

\section{Configurational analysis conceptualizes road networks as the structure of lived space}

Urban space syntax analysis is fairly associated with the analysis of road networks and this can seem a rather instrumental exercise with more relevance to traffic planners than urban historians. It is important in this context to bear in mind the theoretical status of space syntax representations of road networks as just one of a family of syntactical representations of lived space - what Conroy Dalton calls 'embodied diagrams' that differentiates them from abstract planning models. ${ }^{34}$ Sometimes other representations are required, even in urban-scale analyses. Vaughan et al's study of the streets, alleys, courtyards and buildings of London's nineteenth-century East End took a micro-morphological look at the conditions through which a distinctive urban spatial culture emerged for its Jewish community at that time. ${ }^{35}$ The study cross-referenced Goad plans, literary sources, the Booth study notebooks and maps, photographs, contemporaneous descriptions of local street life, minutes of the synagogue societal organisation and newspaper reports. The research team developed a spatial intervisibility analysis of the synagogues, chapels and churches in an area of Whitechapel to consider the ways in which the social-cultural relationships of Jewish inhabitants of the district were shaped by their surroundings. Space syntax analysis was also deployed to discover how the visibility of synagogues from the main street network corresponded to the socio-economic context of their immediate environs.

\footnotetext{
of the Jewish community of the city at the turn of the twentieth century. M. Poutanen and J. Gilliland 'Mapping work in early twentieth-century Montreal: A rabbi, a neighbourhood, and a community', Urban History Review 45, 2 (2017), 7-24.

${ }^{34}$ R. Conroy Dalton, 'Space syntax and spatial cognition', in D. Wu, (ed.), World Architecture: Space Syntax 1, 185 (2005), 41-45.

${ }^{35}$ L. Vaughan and K. Sailer, 'The metropolitan rhythm of street life: a socio-spatial analysis of synagogues and churches in nineteenth-century Whitechapel, in C. Holmes and A.J. Kershen (eds), An East End Legacy: Essays in Memory of William J. Fishman, 184-206 (Abingdon, 2018); also, G. Palaiologou and L. Vaughan, 'Setting up the metropolis: unpacking the historical spatial cultures of London and Manhattan', in Proceedings of the 10th International Space Syntax Symposium, 55:1-18, http://discovery.ucl.ac.uk/1471081/8/SSS10 Proceedings 055.pdf accessed 14 Apr 2019; G. Palaiologou, 'High Street Transactions and Interactions', in L. Vaughan, (ed.), Suburban Urbanities, (London, 2015), 175-203, https://www.uclpress.co.uk/products/83511 accessed 14 Apr 2019.
} 
Pre-publication version: accepted for publication by Urban History 23/9/19, deposited by the authors with UCL RPS 24/9/19

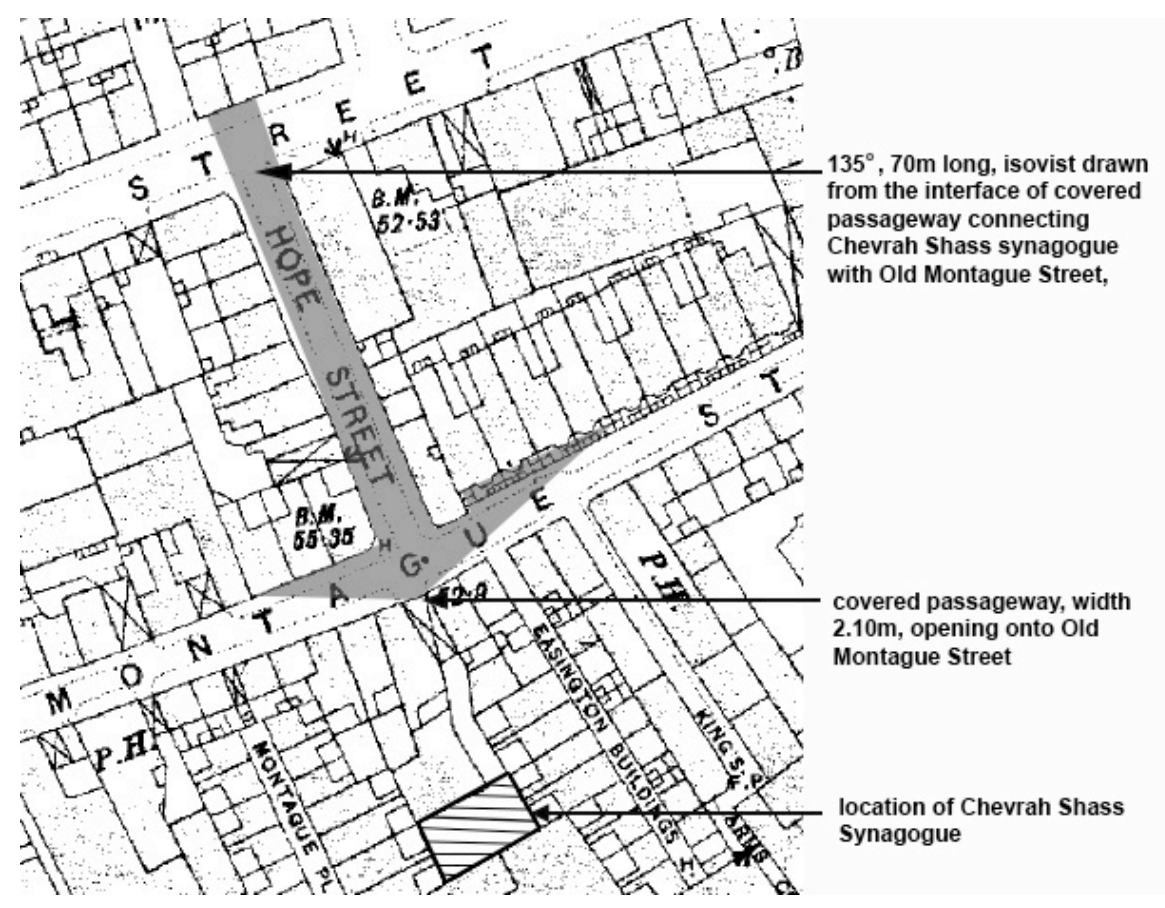

Figure 3: Isovist of Hope Street, Whitechapel, viewed from the interface of Old Montague Street and the passageway leading to Chevrah Shass synagogue c.1890

Image by Laura Vaughan, Kerstin Sailer and Blerta Dino

Figure 3 provides an example of this work that was developed around the elementary syntactic representation of the isovist, a method for describing the visibility relationships of urban space from particular locations on the map. Here, the method was deployed to make a numerical comparison of the visibility and socio-economic setting of twenty-one places of worship within the study area. This distinguished types of synagogues, churches and chapels not only the basis of their architecture but also according to their urban embedding and intravisibility relationships with each other.

$V$. Morphological history helps to explain, as much as it is explained by, the social history of towns and cities

Urban space is not a timeless backdrop to social action but a relational structure through which the temporalities of morphological history and social history interweave to create enduring but complex spatial cultures. ${ }^{36}$ Developing this theme a series of four publications by Griffiths explore the agency of the urban encounter field as a source of routine and ritual in

\footnotetext{
${ }^{36}$ S. Griffiths 'The high street as a morphological event', in Vaughan, Suburban Urbanities, 32-52; J. Hanson, 'Order and structure in urban space: a morphological history of the city of London'. University of London PhD thesis, 1989.
} 
Pre-publication version: accepted for publication by Urban History 23/9/19, deposited by the authors with UCL RPS 24/9/19

the everyday life of Sheffield in the late eighteenth and early nineteenth centuries. Griffiths shows how, in configurational terms, Sheffield's urbanization was characterized by a series of transitions from a relatively sparse nucleated circulatory structure, to an extended area of dense spatial proximity by the mid-nineteenth century, to the emergence of strong linear structures along historical routes connecting the late nineteenth-century web of suburban centres. ${ }^{37}$ Space syntax analysis reveals the multi-dimensional complexity of configurational descriptions that relate to the deep structure of the pre-industrial historical road network. These descriptions were then deployed in more hermeneutical mode to interpret changes in the relationship of home and work and the routes of organized processions in Sheffield, as spatial practices emergent over the nineteenth century. ${ }^{38}$ This transition reveals a gradual symbolic privileging of urban-scale movement in a spatial culture that associated routine bodily mobility with social mobility. The study makes extensive use of archive research, particularly newspaper sources to present a mapping of Sheffield's processional culture onto the dynamics of its quotidian spatial culture, showing how one cannot be properly understood without the other. ${ }^{39}$ This perspective also informs an account of the rise of Sheffield's cutlery industry as a spatial culture of manufacturing, noting how many customary practices in the industry can be interpreted as means to control the easy flow of information that enabled the city to function as 'one great factory', despite an absence of central planning. ${ }^{40}$ Accumulatively these Sheffield studies suggest how space syntax methods can be used to map morphological processes of change and continuity in social spaces, enabling new interpretative possibilities for sources relating to the quotidian life of the cities to emerge.

The morphological history of the suburban built environment of Greater London from c.1820, specifically its role in sustaining socio-economic diversity over time, was the focus of two major EPSRC research projects in the Space Syntax Laboratory. ${ }^{41}$ Here space syntax analysis of Greater London's suburban evolution was combined with traditional sources, principally business directory records, to test hypotheses regarding patterns of spatial continuity and

\footnotetext{
${ }^{37}$ S. Griffiths, 'Persistence and change in the spatio-temporal description of Sheffield parish c.1750-1905', in D. Koch et al (eds), Proceedings 7th International Space Syntax Symposium 37:1-15, http://discovery.ucl.ac.uk/15301/1/15301.pdf.

${ }^{38} \mathrm{~S}$. Griffiths, 'From lines on maps to symbolic order in cities? Translating processional routes as spatial practice, Sheffield c.1780-1910', in Griffiths and von Lünen, Spatial Cultures, 76-94.

${ }^{39}$ S. Griffiths, 'Spatial culture, processional culture and the materialities of social memory in nineteenth-century Sheffield', Distinktion: Journal of Social Theory 17, 3 (2016), 252-275.

${ }^{40}$ S. Griffiths, 'Manufacturing innovation as spatial culture: Sheffield's cutlery industry c.1750-1900', in I. Van Damme, B. Blondé, A. Miles (eds), Cities and Creativity from the Renaissance to the Present (Abingdon, 2017), 127-153.

${ }^{41}$ 2010-13, Adaptable Suburbs, EPSRC EP/I001212/1, http://www.ucl.ac.uk/adaptablesuburbs accessed 31 July 2017; 2006-

09, Towards Successful Suburban Town Centres, EPSRC EP/D06595X/1.
} 
Pre-publication version: accepted for publication by Urban History 23/9/19, deposited by the authors with UCL RPS 24/9/19

change in the relationship between road network, building development and land-use. It showed how the growth processes of Greater London's historical road network was related to the persistence of socio-economic activity within its local town centres. ${ }^{42}$ By enabling diverse, localized patterns of such activity to become accessible at a range of spatialmorphological scales over time, the movement affordances of the historical road network were shown to be a key agent in the unfolding of this dynamic socio-spatial process (Figure $4){ }^{43}$
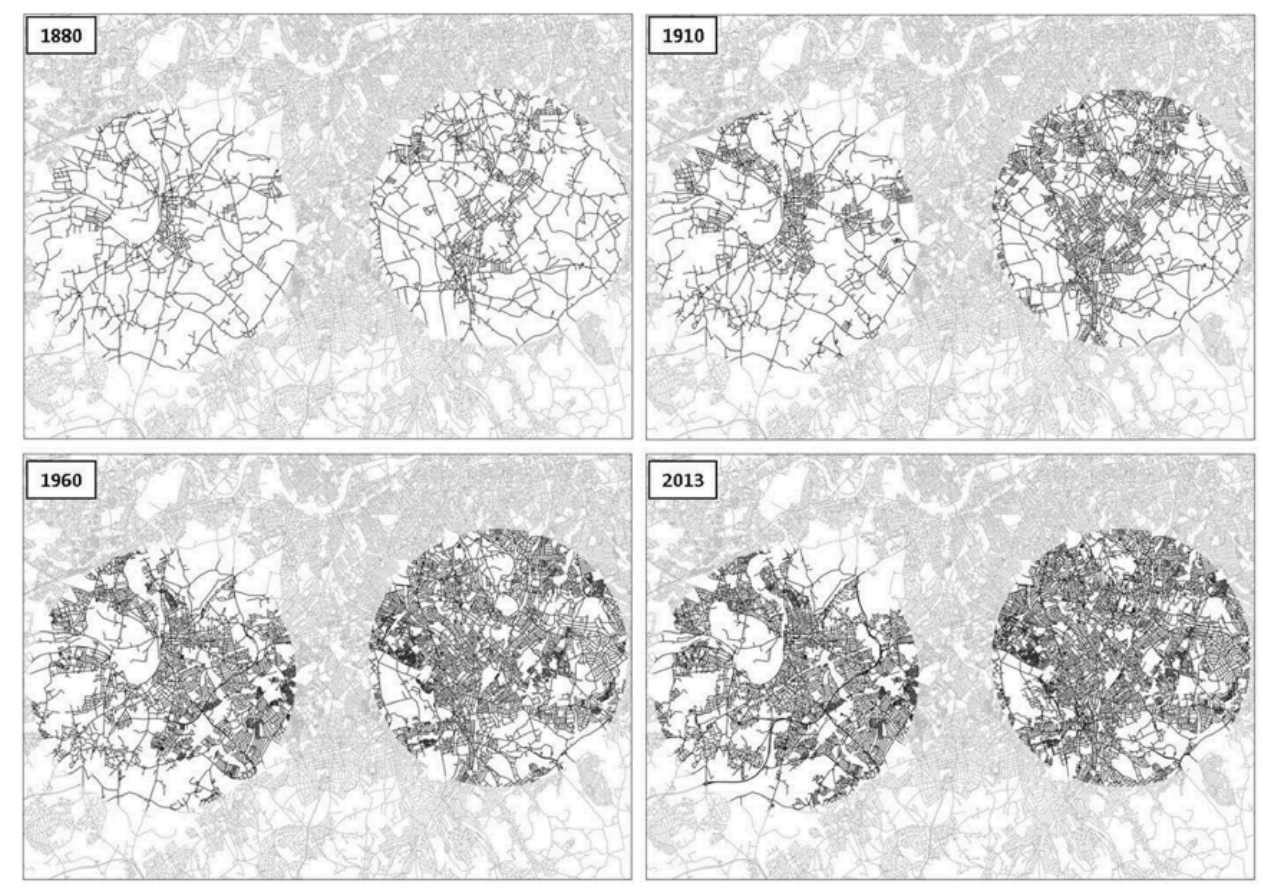

Figure 4: Evolution of the suburban street network in High Barnet (left-hand circle) and

Loughton (right-hand circle) ${ }^{44}$ Image by Ashley Dhanani for the Adaptable Suburbs project

By placing the morphological history of social space in the foreground of the research methodology and examining how the material circumstances of socio-economic arrangements have changed over time, it was possible to offer a different perspective on urban processes to those reinforced by standard periodizations of social history, which tend to render the built environment as relatively static. Focussing on the micro-morphological scale of the individual suburban high street Griffiths considers how analytical work on configurational structures and

\footnotetext{
${ }^{42}$ A. Dhanani 'Suburban Continuity and Change', in Vaughan, Suburban Urbanities, 53-76.

${ }^{43}$ Griffiths et al. 'The persistence of suburban centres in Greater London'; I. Törma, S. Griffiths and L. Vaughan, 'High street changeability: the relationship between morphology and demolition, modification and use change in two south London suburbs', Urban Morphology 17, 1 (2017), 5-28.

${ }^{44}$ Contains Ordnance Survey data (C) Crown copyright and database right 2014.
} 
Pre-publication version: accepted for publication by Urban History 23/9/19, deposited by the authors with UCL RPS 24/9/19

land use patterns stimulates a consideration of the role of the built environment in perpetuating community as a 'performance' that normally extends beyond the life spans of thee individuals who inhabit it for any given period. ${ }^{45}$ It was argued that the high street constitutes a site for negotiating modes of historical continuity, expressed as a capacity for negotiating on-going social change in local contexts. In a similar vein, Tom Bolton's research into the evolution of railway neighbourhoods illustrates how historical investigation the combines land use mapping, space syntax and built form analysis, coupled with a thick textual description of the social and economic characteristics of the city, can provide evidence for the manner in which early decisions regarding the siting of railway infrastructure can set in two long-term processes of urban formation widely identified as being on the 'wrong side of the tracks'.46

\section{From maps to mapping using space syntax}

Space syntax has its origins in research undertaken at the Bartlett School of Architecture during the $1970 \mathrm{~s} .{ }^{47}$ For its principal founders Bill Hillier and Julienne Hanson, space is the existential problem that society (an intangible abstraction) must 'overcome' through its material (architectural) organization and the cultural codes that co-evolved to control patterns of potential co-presence, movement and encounter between different social groups. ${ }^{48}$

Space syntax theory proposes that maps and plans are not only semiotic constructions representing the mapmaker's worldview but also diagrams that encode spatial-morphological descriptions of inhabited space as an intersubjective domain of movement and encounter. Rendered as networks and analysed as graphs using space syntax methods and software, these numeric forms of description are said to be 'non-discursive', as they denote complex spatial

\footnotetext{
${ }^{45}$ S. Griffiths 'The high street as a morphological event'; Vaughan illustrates the nature of historical continuity with a painting from c. 1830 by John Constable that shows Sir Richard Steele's Cottage, Hampstead in the foreground and St Paul's Cathedral in the background, to highlight both the process of urban change - Hampstead was an outlying suburb at time, while today is considered part of London - and the continuity of urban elements despite that change. The continuity of the road section depicted as the locus for drinking culture in a succession of inns and pubs 'signals a kind of path dependency that is one of the ways in which cities such as London have managed to adapt to change' L. Vaughan, 'Introduction: suburbs are as old as the city itself', in Vaughan (ed.), Suburban Urbanities, 5-6,

${ }^{46}$ T. Bolton, 'Railway terminals and separation: Paddington and Marylebone Stations, London', in. J. Clark and N. Wise (eds), Urban Renewal, Community and Participation: Theory, Policy and Practice J. (Dordrecht, 2015), 125-140. The essential study by Richard Rodger on the transformation of Edinburgh in the nineteenth century demonstrates the importance of mapping historical land use patterns to capture the impact of urban interventions. Rodger finds that 'as in other Victorian cities, the lines of railway development shaped subsequent housing development and crystallised existing zones of land use.' R. Rodger, The Transformation of Edinburgh: Land, Property and Trust in the Nineteenth Century, (Cambridge, 2004$), 211$. ${ }^{47}$ Hillier and Hanson, The Social Logic of Space; B. Hillier, Space is the Machine (Cambridge, 1996); J. Hanson, Decoding Homes and Houses (Cambridge, 1998).

${ }^{48}$ Hillier and Hanson, The Social Logic of Space, 236.
} 
Pre-publication version: accepted for publication by Urban History 23/9/19, deposited by the authors with UCL RPS 24/9/19

arrangements of material phenomena that can only be described quantitatively, (at least in the first instance), and in that sense evade conventional linguistic definition. In space syntax theory these spatial descriptions signify the configurational qualities of what Hillier refers to as the 'encounter field'; ${ }^{49}$ the complex arrangements of social interfaces regulating patterns of co-presence and interaction that he regards as the essential 'raw material' for social life of any kind to take place. ${ }^{50}$ Historical research in spatial cultures focuses on articulating the spatiomorphological and socio-economic definition of the urban encounter field within a single explanatory framework.

In advocating space as a useful category of historical analysis ${ }^{51}$ it is important to acknowledge the concerns of most social theorists of space that to engage with formal spatial analysis is to invite the temporal and cultural decontextualization of the subject. From the mid nineteenthcentury Ordnance Survey in Britain was deploying sophisticated technologies to produce Euclidean cartographic surveys to a high degree of precision, largely for facilitating tasks of state governance. The process through which these maps were produced, however, selfevidently entailed relatively little embodiment of the urban experience itself. In this sense official cartography indeed represents statist and capitalist power vectors - what Michel de Certeau calls the 'strategic' views of those in possession of power. ${ }^{52}$ For the social anthropologist Tim Ingold such an absolute separation between map production and the populations whose place of living and working constitute the cartographic object, is both symptomatic and generative of social alienation. ${ }^{53}$ For Ingold the tacit assumption that the operation of 'mapmaking' involves an unmediated transcription from the structure of the world to the structure of the map characterizes the 'cartographic illusion', since in reality it is the mapmaker's world that is being represented. ${ }^{54}$ While we acknowledge this argument is it not equally possible that the mapmaker's operation may also translate other dimensions of social information into cartographic form (for example, pertaining to material, spatialmorphological relationships alongside those pertaining to ideological, conceptual ones)? In other words, is Ingold correct in collapsing absolutely the cartographic representation of the urban built environment into a hegemonic strategy of symbolic ordering, or does the

\footnotetext{
${ }^{49}$ Hillier, 'The architecture of the urban object'.

${ }^{50}$ Hillier, Space is the Machine, 141.

${ }^{51}$ L. Jerram, 'Space: a useless category for historical analysis?', History and Theory, 52 (2013), 400-419.

${ }_{52}^{52}$ M. de Certeau The Practice of Everyday Life (Berkeley, 1984).

${ }^{53}$ T. Ingold, The Perception of the Environment: essays on livelihood, dwelling and skill (2000), 234.

${ }^{54}$ Ibid 234.
} 
Pre-publication version: accepted for publication by Urban History 23/9/19, deposited by the authors with UCL RPS 24/9/19

cartographic diagram retain traces of socio-spatial formations that escape, or at least are not categorically reducible to, such an ordering process?

For Ingold the map as a cartographic output of a scientific process is distinguished from mapping as an embodied cultural practice. Mapping in this sense involves human agents in the bodily re-enactment of movements in performative mode, whether by re-tracing the steps of a journey or through recounting its itinerary through speech and gesture, sometimes with the aid of inscriptive tools such as pens. Interestingly Ingold finds equivalence between mapping as a narrative device of communal remembering in indigenous communities and the gestural act of marking a journey on a contemporary published map, with the crucial qualifier that such a marking would commonly be regarded as a defacement rather than a narrative telling. Yet such defacements have long been part of the Situationist and psychogeographer's visual repertoire, and are not running a fingernail along the streets of an intended case-study area an act of defacement that most urban historians commit - it is certainly gestural?

Ingold's argument is revealing because it suggests how the fundamental space syntax representational diagram of the urban street network - the axial map - could be considered as a defacement of the cartographic object in Ingold's sense. Unlike the itinerary of the psychogeographer it provides an allocentric (that is, all point to all point) network description of the urban encounter field rather than an egocentric diary of a particular route. An axial map (or graph) consists of a network or configurational model that renders urban built form as the longest and least set of lines that connect all the areas of open space (see above, Figure 1, for an example of a similar space syntax representation, the segment map, that is derived from an underlying axial model). ${ }^{55}$ The axial map is then processed in a computer to produce a range of syntactic variables, for example measuring the relative depth of a given space within the urban system of spaces, as a starting point for exploring social phenomena such as probable levels of pedestrian activity.

Urban-scale space syntax as a mapping method begins from the axial map as a radical simplification and abstraction of the system of open space represented in the cartographic basemap. Yet before high-speed graph processing computer software became readily

\footnotetext{
${ }^{55}$ Hillier and Hanson, The Social Logic of Space, 99.
} 
Pre-publication version: accepted for publication by Urban History 23/9/19, deposited by the authors with UCL RPS 24/9/19

available space syntax variables were calculated manually from graphs showing the connectivity of axial lines drawn onto tracing paper overlaid on the basemap (typically an Ordnance Survey map). This method necessitates a meticulous mapping process which involves sustained reflection about the structure of the cartographic representation and how it functioned as a lived space, as well as an ability to step back from the semiotic content of the basemap to the overall configuration of a settlement pattern. ${ }^{56}$

The increasing use of road-centre line data to produce large space syntax models of contemporary cities means analogue, (after Ingold we might say 'gestural' techniques) such as tracing by hand are now uncommon in most areas of space syntax research. The action of drawing on tracing paper over a basemap remains implicit (and, epistemologically speaking, vital), however, in admitting the degree of variability in spatial modelling that liberates syntactic representations to be developed in the context of specific historical research questions rather than simply as models applied on a one-size fits all basis. This scope for variability (for example as to the resolution at which the axial map is constructed) allows town-plan analysis using space syntax to represent the historical built environment as an encounter field in an open-ended manner, embracing the material nature of lived space without excluding the socio-economic and cultural contexts in which encounter fields emerge and are controlled. ${ }^{57}$

Surprisingly perhaps, Hillier's emphasis on urban space as a non-determining or 'probabilistic' encounter field (as opposed, for example, to a 1:1 correspondence between the spatial-morphology of a street layout and patterns of movement and interaction) resonates with Ingold's emphasis on the impossibility of social structure being mapped onto the material world in its own image - the source of the 'cartographic illusion'. Hillier et al are similarly categorical on this point. ${ }^{58}$ They claim that spatial configuration (as, for example, represented in an axial map) offers an 'alternative basis for encounters' to that 'dictated by the social structure', it describes a complex performative field in which individualized spatial

\footnotetext{
${ }^{56}$ R. Conroy Dalton, 'Space syntax and spatial cognition'.

${ }^{57}$ S. Griffiths, 'Space syntax as interdisciplinary urban design pedagogy', in M. Carmona (ed.), Explorations in Urban Design: an urban design research primer (Farnham, 2014). S. Griffiths and V. Netto, Guest Editorial 'Open syntaxes: towards new engagements with social sciences and humanities', Journal of Space Syntax 6, 1 (2016), ii-v, http://discovery.ucl.ac.uk/10039192/ accessed 14 Apr 2019.

${ }^{58}$ B. Hillier, A. Leaman, P. Stansall and M. Bedford . 'Space syntax', Environment and Planning B: Planning and Design, 3 , 179-80.
} 
Pre-publication version: accepted for publication by Urban History 23/9/19, deposited by the authors with UCL RPS 24/9/19

practice may become collectively communicated as meaningful social practice. ${ }^{59}$ The axial map, in other words, represents the spatio-morphological dimension of cartographic productions that, while it certainly does not escape definition in socio-economic or cultural terms, neither is it wholly reducible to socio-economic or cultural explanation. ${ }^{60}$

In historical research one must, necessarily, rely on cartographic sources since the historical built environment it represents is in the past. Given this profound limitation it is important to note how Ingold's concern that scientifically cartography collapses the openness of reality into the totality of the mapped representation), has its anti-materialist counterpart in the sort of cultural reduction that translates the myriad possibilities of everyday social spaces into restatements of hegemonic cultural codes. Historical work using space syntax takes seriously the proposition that, after Lefebvre, acknowledging the sociality of space means assigning a degree of social agency to material arrangements that conform to the artefactual (that is morphological or configurational) principles that give an intelligible definition to material arrangements in time and space. This disjunction of the spatio-morphological and the cultural is reminiscent of Lefebvre's distinction between the material 'texture' of the lived city and text itself as constituting different kinds of hermeneutical object. ${ }^{61}$

Space syntax then, is not offered as an instrumental 'technique' but as a theory of sociospatial description distinguished by its ability to make the link from relatively static material formations to social processes. A core proposition in this respect is that the encounter field described by the spatial configuration of a street network is typically anterior to the emergence of specific land-use attractors (for example, significant sites such as churches or town halls) in shaping possible patterns of movement in urban space - in other words the configuration of the urban grid itself is the primary source of movement dynamics. The diagram in Figure 5 illustrates the space syntax theory of 'natural movement'. It illustrates how the spatial configuration of built form generates patterns of movement and attraction in urban space. While these can influence each other, core space syntax theory starts from the premise that movement and attraction do not themselves affect configuration. ${ }^{62}$ The theory of

\footnotetext{
${ }^{59}$ V. Netto, The Social Fabric of Cities, (Abingdon, 2016).

${ }^{60}$ D. Seamon, A Geography of the Lifeworld: Movement, Rest and Encounter (New York, 1979).

${ }^{61}$ H. Lefebvre, The Production of Space, trans D.N. Smith (Oxford, 1991), 132; 137.

${ }^{62}$ The assertion that movement and land use attractors cannot change spatial configuration is empirically questionable because, over time, these may generate new paths through space, with corresponding configurational effects. Hillier's
} 
Pre-publication version: accepted for publication by Urban History 23/9/19, deposited by the authors with UCL RPS 24/9/19

natural movement enables space syntax theory both to classify urban types according to the 'social logic' of given morphological arrangements, while also revealing space as an agent in organizing the complex patterning of social life 'on the ground'.

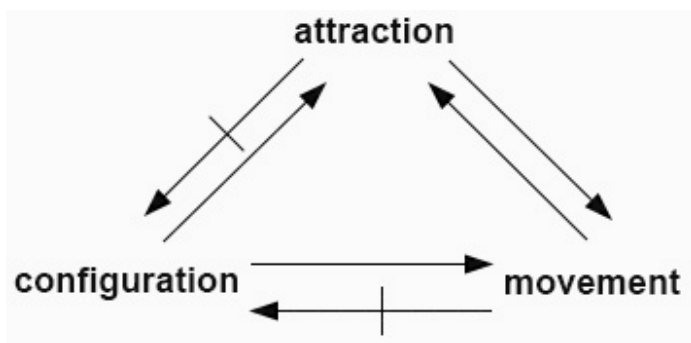

Figure 5: The relationship of configuration, attraction and movement in space syntax theory ${ }^{63}$

Ingold's theorization of mapping offers a powerful critique of the cartographic productions of modernity that is widely and legitimately endorsed by much urban historiography. An undesirable consequence of this critique, however, has been to contribute to the relegation of the epistemological status of the map for research into the material conditions and practices of everyday urban life. Asserting that modern-era cartographic surveys encode spatialmorphological as well as semiotic information is not to conflate the cartographic representation of reality with reality itself. Rather the argument is that a map considered as a spatial-morphological description of the urban past does not neatly conform to the same map conceived as an ideological description. Spatial-morphological descriptions are defined by the relative positioning of the material objects (i.e. buildings) represented on the map, rather than their symbolic positioning in ideological landscapes described by Ingold's human subjects. It is in revealing this disjunction between material affordance and symbol that map analysis using space syntax can offer new possibilities for research in urban history.

\section{Historiographical contexts}

The marginalization of $u n$ - or mis- represented urban populations is especially relevant to the historiography of the nineteenth-century industrial city. Durkheim characterized urban modernity in terms of its physical and moral density, making an intimate connection between the form and content of social life (what he refers to as 'social morphology') in cities inflated

\footnotetext{
concern, however, is to establish configuration as primary in the synchronic model. This question is addressed in S. Griffiths, 'Temporality in Hillier and Hanson's theory of spatial description'.

${ }^{63}$ Redrawn from B. Hillier, A. Penn, J. Hanson, T. Grajewski, J. Xu, 'Natural movement: or, configuration and attraction in urban pedestrian movement', Environment and Planning B: Planning and Design, 20 (1993), 31.
} 
Pre-publication version: accepted for publication by Urban History 23/9/19, deposited by the authors with UCL RPS 24/9/19

by unprecedented population growth. ${ }^{64}$ The urbanization associated with industrialization explains why Britain gave rise to the phenomenon of the social reformer as urban investigator engaged with surveying and tabulating the conditions of life in the 'uncharted territory' of the mushrooming industrial towns. ${ }^{65}$ Both as physical and social environments these places were as alien to the understanding and taste of classically educated elites as the imperial acquisitions in India and Africa were to the mass of the British population. The founder of the Salvation Army William Booth made this association explicit in comparing the slums of contemporary cities to the jungles of equatorial Africa - both were, he believed, equally godless and removed from civilization. ${ }^{66}$ At about the same time William Booth's contemporary, the social reformer Charles Booth, was producing his pioneering street maps that revealed to the educated British public the extreme contrasts of wealth and poverty that existed cheek by jowl in London. The development of mapping technologies and practices, by organizations as diverse as Ordnance Survey, Temperance societies, municipal boundary commissions and fire insurance companies all emerged in the broader context of the nineteenth-century reformist enthusiasm to map the 'urban interior'. Recent urban historians have tended to interpret the nineteenth-century enthusiasm for mapping in terms of a Foucauldian push for social control. Here mapping technologies are said to be explicitly political in enabling middle-class elites and the imperialist state to assert spatial order as a means of enforcing ideological discipline on anonymous and potentially revolutionary, urban populations. $^{67}$

From a space syntax perspective, however, the cultural framing of cartographic productions does not invalidate the value of maps as rich records of past material realities a priori, no matter how epistemologically compromised they may be. Of course, in disciplines such as archaeology, historical geography and urban morphology, a considerable amount of analytical precision has long been applied to the material culture of urban development. ${ }^{68}$ Nor should scholarly historians write off as 'naïve' the priority given to maps and photographs of the

\footnotetext{
${ }^{64}$ J.A. Banks, 'The contagion of numbers', in H.J. Dyos and M. Wolff (eds), The Victorian City: Images and Realities, Volume 1, (London, 1976), 105-22; L.S. Liebst, 'Reassembling Durkheimian sociology of space', in S. Griffiths and A. von Lünen, Spatial Cultures, 214-224.

${ }^{65}$ A. Briggs, 'The human aggregate', in H.J. Dyos and M. Wolff, The Victorian City, 83-104; G. Davison, 'The city as a natural system: theories of urban society in early nineteenth-century Britain', in D. Fraser and A. Sutcliffe (eds), The Pursuit of Urban History, (London, 1983), 349-370.

${ }^{66}$ W. Booth, In Darkest England and the Way Out (London, 1891), 9.

${ }^{67}$ For example, P. Joyce, The Rule of the Freedom: Liberalism and the Modern City (Saffron Walden, 2003).

${ }^{68}$ P. Johnson and M. Millet, (eds), Archaeological Survey and the City, (Oxford, 2013); H. Carter, An Introduction to

Historical Geography, (1983); M.R. G. Conzen, Alnwick, Northumberland: a study in town-plan analysis, (London, 1960).
} 
Pre-publication version: accepted for publication by Urban History 23/9/19, deposited by the authors with UCL RPS 24/9/19

built environment in local and community histories. ${ }^{69}$ But if, as R.G. Collingwood argued, history is basically 'humanistic' in the sense that it is concerned with what people have done in the past and constructs its narratives on this basis, then something more is required to better engage mainstream historical studies with the kind of analytical work on built form for which maps and plans are core source materials. ${ }^{70}$

This is especially true of research on British cities from at least the eighteenth century where the profusion of textual and visual sources available means the interdisciplinary concerns of built environment specialists may seem of marginal interest. As the urban morphologist Michael Conzen has reflected, scholars in his field of research have shown little interest in history as historians recognize it, and vice-versa. ${ }^{71}$ The result is that the conceptual link between the organization of built form (the material basis of everyday life) and what people do, think and mean (i.e. quotidian urban culture) remains under conceptualized. As late as 2000 Colin Pooley could state that despite the theoretical strides made by Henri Lefebvre and David Harvey in explaining the social nature of space, and after decades of cartographicallybased research into questions such as residential segregation, the 'extent to which changes in urban structure altered people's lives is often little more than conjecture'. ${ }^{72}$ This situation seems unlikely to change in the face of a de facto division of labour between contradictory epistemological positions in the humanities and social sciences in which maps are viewed primarily as cultural texts or as elementary indices of physical urban transformation.

If, however, maps are not viewed exclusively through contrasting disciplinary lenses then how might they be usefully interrogated as historical sources for a better understanding everyday urban life, but without risking deterministic associations between the materiality of built form, what it does (functionally) and what it means (socially)? Lefebvre established that space is erroneously conceptualized as a passive container of social life. ${ }^{73}$ Yet the principal legacy of historians adopting his line on the 'social production' of space has been to cast space in abstract, immaterial terms as the ideological formation of macro socio-economic

\footnotetext{
${ }^{69}$ G. Oliver, Photographs and Local History, (London, 1989).

${ }^{70}$ R.G. Collingwood, The Idea of History (Oxford, 1961), 18.

${ }^{71}$ M.P. Conzen, 'The elusive common denominator in understanding urban form', Urban Morphology 14, 1 (2010), 55-58.

72 C. Pooley 'Patterns on the Ground', 465.

73 This position has achieved acceptance across a wide range of periods in mainstream social history, for example D. Newsome, 'Introduction: making movement meaningful', in R. Laurence and D. Newsome (eds), Rome, Ostia, Pompeii: Movement and Space (Oxford, 2011), 1-56; B. Kumin, (ed.), Political Space in Early-Modern Europe (Farnham, 2009); S. Sleight, Young People and the Shaping of Public Space in Melbourne 1870-1914 (Farnham, 2013).
} 
Pre-publication version: accepted for publication by Urban History 23/9/19, deposited by the authors with UCL RPS 24/9/19

processes. ${ }^{74}$ For all Lefebvre's own emphasis on 'spatial practice' and 'lived space' his influence on social history has largely been to sustain a strongly cultural emphasis on cartography as a system of ideologically encoded 'representations of space', that alienates rather than, in any sense, records material reality. This epistemological difficulty has, of course, not prevented many historians from engaging with the built environment in their research into quotidian urban life. ${ }^{75}$ One must conclude, however, that they are doing so in the absence of the conceptual and methodological tools that would both facilitate and create fresh opportunities for their research. In short, there is an epistemological need for a conceptually reflexive mode of map analysis able to express the materiality of social space without sacrificing the sociality of social space. ${ }^{76}$

Addressing this question requires a return to the sometimes vexed question of methodology in historical studies. ${ }^{77}$ We maintain that urban historians could find value in reconnecting with a neglected historiography in which maps and plans are approached as much for what they say about urban life as much as how they frame it ideologically. ${ }^{78}$ So far spatial humanities as a nascent interdisciplinary domain has been, arguably, less about rediscovering maps as sources per se so much as deploying a particular technology, GIS, to give precise spatial definition to a range of historical, literary and cultural sources. ${ }^{79}$ In its early days Historical GIS (HGIS) could be fairly criticized as an exercise in large-scale data cataloguing, often conducted at some remove from the research interests and skill sets of practising urban historians. The epistemological ground is rapidly shifting, however, as on-going interdisciplinary engagement identifies new topics where GIS technology can be productive for historians, notably in areas of applied and public history. ${ }^{80}$ There is still much work to do, however, in identifying at a

\footnotetext{
${ }^{74}$ L. Jerram, 'Space: a useless category for historical analysis?'.

${ }^{75}$ L. Jerram, Streetlife: The Untold History of Europe's Twentieth Century (Oxford, 2011).

${ }^{76}$ Current work by historians interested in mapping demonstrates both the achievements and challenges of interdisciplinary work, for example: K. Navickas, 'Political Meetings Mapper' http://politicalmeetingsmapper.co.uk/maps/ accessed 5 Feb, 2019; V. Brown's mapping of the Jamaican Slave Revolt 1760-61 http://revolt.axismaps.com/map/ accessed 5 Feb 2019, also V. Brown 'Mapping a Slave Revolt Visualizing Spatial History through the Archives of Slavery', Social Text 33, 4, 125 (2015), 134-141. The reconstruction of nineteenth-century Sheffield as a three-dimensional architectural model as part of the Materializing Sheffield project raises some intriguing epistemological questions about accessing the materiality of the urban past https://www.hrionline.ac.uk/matshef/ accessed 5 Feb 2019.

${ }^{77}$ S. Gunn and L. Faire, 'Introduction: why bother with method?' in Gunn and Faire (eds), Research Methods for History (Edinburgh, 2012), 1-12; S. Rau and E. Schönherr, 'Preface', in Rau and Schönherr (eds), Mapping Spatial Relations, their Perceptions and Dynamics: the City Today and in the Past (Dordrecht, 2014), v-ix.

${ }^{78}$ This historiography dates from at least the 1960s and is associated with the work of Harold Dyos, Asa Briggs, Michael Wolff, Anthony Sutcliffe, Derek Fraser and David Reeder among others.

${ }^{79}$ Gregory and Ell, Historical GIS; D.J. Bodenhamer, 'The spatial humanities: space, time and place in the new digital age', in T. Weller (ed.), History in the Digital Age (Abingdon, 2013), 23-38.

${ }^{80}$ The recent AHRC sponsored MESH (Mapping Edinburgh's Social History) project at the University of Edinburgh is an ambitious public history project that integrates a vast range of cartographic and geocoded historical datasets
} 
Pre-publication version: accepted for publication by Urban History 23/9/19, deposited by the authors with UCL RPS 24/9/19

conceptual level what Historical GIS (HGIS) can do, that goes beyond accelerating the task of putting dots on maps to offer genuinely innovative interpretative possibilities for traditional (and necessarily finite) historical source materials. ${ }^{81}$ While HGIS undoubtedly offers a very useful platform for the spatial analysis and visualization of historical data it does not, as a set of tools, address the conceptual problem of linking urban materiality with the sociality of space, yet this issue must lie at the heart of the debate regarding the epistemological value of developing map analysis as a serious research method for urban history.

\section{Conclusion}

Advocacy of the space syntax approach to historical mapping understandably elicits the suspicion that a set of technologically enabled techniques threatens to intervene in the vital dialogue of the historian with his or her sources. We have argued that, on the contrary, map analysis using space syntax can help advance this dialogue by re-presenting the cartographic image as an encounter field generative of spatial cultures, rather than as a physical backdrop or cultural mirror. Producing space syntax data by notionally 'defacing' the town plan with axial lines would be characterized by the philosopher of science Ian Hacking as the "creation of phenomena' ${ }^{82}$ Historians may be reluctant to engage with created data sources because they lack tangible presence in the archive and therefore may be regarded as inauthentic. Yet historical accounts that assume something about how space functions socially for movement and encounter, often in the absence of any firm theoretical or evidential basis for this assumption, make a strong case for engaging with the theories and methods of space syntax. Such an engagement has implications for the historian's use of language, since space syntax descriptions of urban space are quantitative and visual, leaving to the historian the job of interpreting the data in the light of other sources and contextual knowledge. This interpretative process is open-ended as configurational descriptions of space are said by Hillier to be 'non-discursive' in that, as numeric expressions, they lack exact referents in natural language. Indeed, it is precisely the capacity of the material organization of social

https://www.ed.ac.uk/history-classics-archaeology/research/research-projects/mapping-edinburgh-s-social-history accessed 5 Feb 2019.

${ }^{81}$ A. von Lünen, 'Tracking in a new territory: re-imaging GIS for history', in A. von Lünen and C. Travis, (eds), History and GIS: Epistemologies, Considerations and Reflections (Dordrecht, 2013), 211-239; S. Griffiths, 'GIS and research into historical "spaces of practice".

${ }^{82}$ I. Hacking, Representing and Intervening: Introductory Topics in the Philosophy of Natural Science (Cambridge, 1983). 
Pre-publication version: accepted for publication by Urban History 23/9/19, deposited by the authors with UCL RPS 24/9/19

space to resist absolute semantic definition that explains why it cannot be reduced to cultural representation. $^{83}$

Configurational analysis shows how spatial nouns from 'ghetto' and 'slum' to 'street', thoroughfare' and 'square' present generic linguistic categories lacking in clear historical definition. Such terms have broad resonance in the historiography of the nineteenth-century city but tend to conceal significant differences between social spaces and their socioeconomical functions in relation to the wider urban context. The space syntax perspective on map analysis is useful to those who would guard against the conflation of maps as cultural productions with the lives of people who lived and worked in the urban spaces they represent. ${ }^{84}$ It demonstrates the aptness of E.P. Thompson's response to the critique of historical research methods by Marxist social theorists, that the empirical mode of historical investigation is not to be conflated with 'empiricism' as an ideological formation. If the formal analysis of maps and plans using space syntax can help historians to get more from these sources and access the urban past in new ways then this is surely sufficient justification for advocating their use in historical research - it does not diminish the task of proper contextualization and interpretation. ${ }^{85}$

\footnotetext{
${ }^{83}$ Hillier, Space is the Machine, 88-145.

${ }^{84}$ A. Mayne, A. and T. Murray, 'The Archaeology of Urban Landscapes: Explorations in Slumland', in Mayne and Murray (eds), The Archaeology of Urban Landscapes: Explorations in Slumland (Cambridge, 2001), 1-7.

${ }^{85}$ E.P. Thompson, The Poverty of Theory and Other Essays, (London, 1978), 197-98.
} 